Portland State University

PDXScholar

10-19-1977

\title{
Measurement of Ambiguity Tolerance (MAT-50): Further Construct Validation
}

Burl Mostul

Portland State University

Follow this and additional works at: https://pdxscholar.library.pdx.edu/open_access_etds

Part of the Psychology Commons

Let us know how access to this document benefits you.

\section{Recommended Citation}

Mostul, Burl, "Measurement of Ambiguity Tolerance (MAT-50): Further Construct Validation" (1977). Dissertations and Theses. Paper 2514.

https://doi.org/10.15760/etd.2511

This Thesis is brought to you for free and open access. It has been accepted for inclusion in Dissertations and Theses by an authorized administrator of PDXScholar. Please contact us if we can make this document more accessible: pdxscholar@pdx.edu. 
AN ABSTRACT OF THE THESIS OF Burl Mostul for the Master of Sclence In Psychology presented October 19, 1977.

Title: Measurement of Ambiguity Tolerance (MAT-50): Further Construct Valldation.

APPROVED BY MEMBERS OF THE THESIS COMMITTEE:

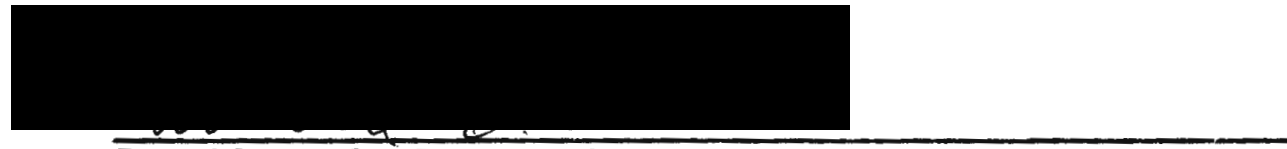

Ronald Smith, Ph.D., Chairperson

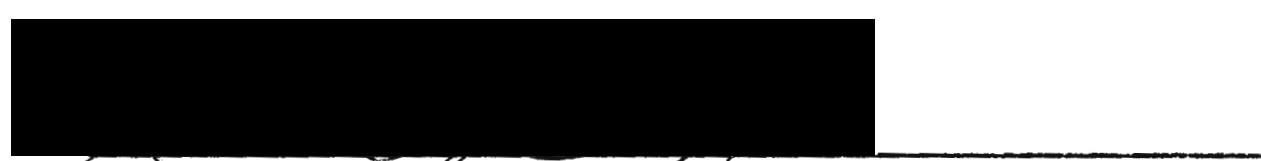

Robert E. Jones, Jr., Ph.D?

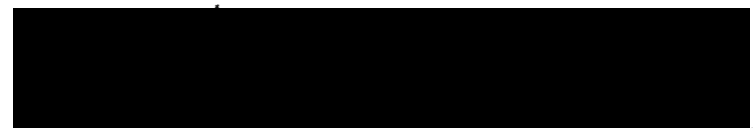

Hugo Maynard, Ph.D.

An historfcal introduction is made tying authoritarianism with ambigulty tolerance. Ambiguity tolerance is a personality variable in Its own right, often assoclated with authoritarlanism yet remalining separate from $1 t$.

Ambiguity intolerance is defined as the tendency to perceive and Interpret information that is marked by vague, fragmented, incomplete, inconsistent, contradictory, or unclear meaning as actual or potential sources of psychological threat. Ambiguity tolerance is defined as the tendency to percelve ambiguous situations as challenging and desirable. 
Efforts to measure ambiguity tolerance have met with varied success, however, it was not unt11 Norton (1975) developed the Measurement of Ambiguity Tolerance (MAT-50) that accurate measurement became a possibility. The present study presents data that provides some construct validity to the MAT-50.

College students were administered the MAT-50 and divided into two groups: tolerants and intolerants. It was hypothesized that individuals who were in the intolerant group would produce more anxiety (as measured by the State-Trait Anxiety Inventory) when presented w1th an ambiguous Bituation (the Rorschach inkblot test) than Individuals in the tolerant group. The hypothesis was confirmed, individuals in the intolerant group displayed more state as well as trait anxiety than those in the tolerant group. Recomendations are made suggesting that future research use subjects from a less homogenous group. 
MEASUREMENT OF AMBIGUITY TOLERANCE (MAT-50):

FURTHER CONSTRUCT VALTATION

by

BURL MOSTUL

A thesis submitted in partial fulfillment of the requirements for the degree of

\author{
MASTER OF SCIENCE \\ in \\ PSYCHOLOGY
}

Portland State University

1977 
TO THE OFFICE OF GRADUATE STUDIES AND RESEARCH:

The members of the Committee approve the thesis of

Burl Mostul presented October 19, 1977.

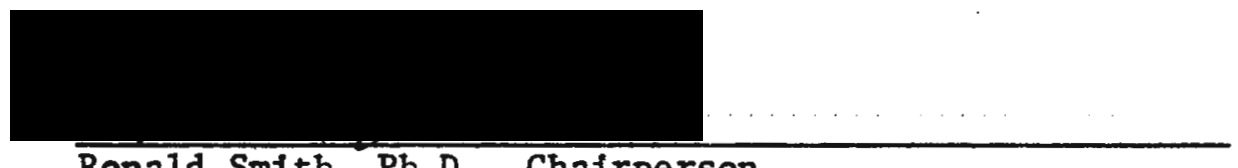

Ronald Smith, Ph.D., Chairperson
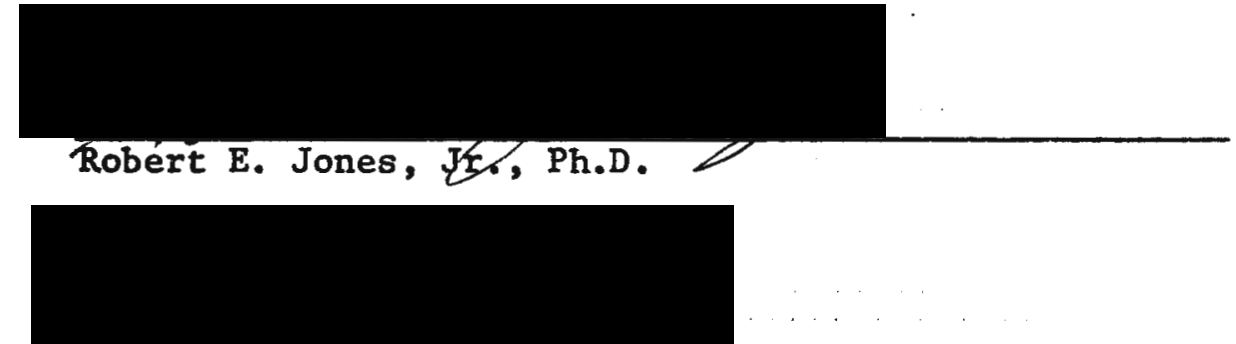

Hugo Kaydard, Ph.D.

APPROVED :

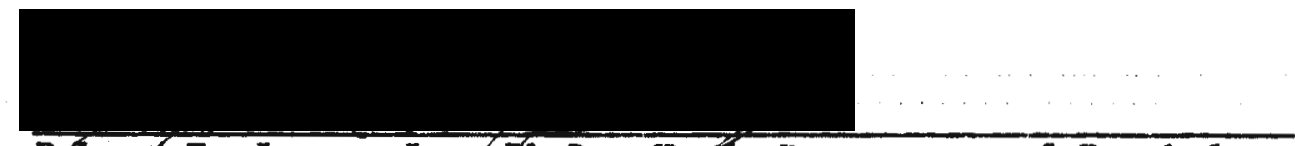

Róbert E. Jones, Jr. Ph.D., Head, Department of Psychology

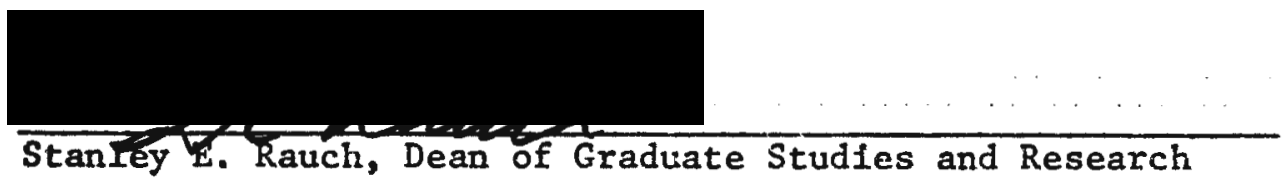




\section{ACKNOWLEDGMENTS}

The author wishes to extend his thanks and appreclation to his thesis committee who were very understanding and especially to his chairman who clearly went beyond the call of duty in providing afd and suggestions. The author also wishes to thank Lisa Demian, Robert Jones, Diane Michel, Cheryl Morrow, and Robert Powloskt for providing the author with subjects for research. Most important, however, the author thanks Sharon Gorgas who provided constructive criticism, corrected numerous spelling errors, and helped motivate the author, as well as typing a manuscript that any ordinary typist would find impossible. 
TABLE OF CONTENTS

PAGE

ACKNOWLEDGEMENTS ....................... III

LIST OF TABLES . . . . . . . . . . . . . . . . . v

CHAPTER

I HISTORICAL INTRODUCTION . . . . . . . . . . . 1

II DEFINITION OF AMBIGUITY TOLERANCE . . . . . . . . 2

III PERSONALITY CORRELATES .............. 6

Ambiguity Tolerance

Ambiguity Intolerance

IV DEVELOPMENTAL HYPOTHESIS . . . . . . . . . . 9

V MEASUREMENT OF AMBIGUTTY TOLERANCE . . . . . . . . . 11

The MAT-50

VI EXPERTMENTAL METHOD AND TECHNIQUE . . . . . . . . 13

Method

Subjects

Rationale

Hypothesis

Results

VII CONCLUSIONS AND RECOMMENDATIONS . . . . . . . . 17

BIBLIOGRAPHY . . . . . . . . . . . . . . . . . . 19

APPENDIX .. . . . . . . . . . . . . . . 22 


\section{LIST OF TABLES}

TABLE

PAGE

I. Uses of the Term Amblguous ............... 3

II. Analysis of Variance -- State Anxiety . . . . . . . 15

III. Analysis of Variance -- Trait Anxiety . . . . . . . 16

IV. Abstract of MAT 50 scores . . . . . . . . . 16 


\section{HISTORICAL INTRODUCTION}

Historically, tolerance to ambiguity has of ten been referred to in conjunction with personality variables such as rigidity, prejudice, authoritarianism, dogmatism and ethnocentrism. Primary in this list of personality variables is authoritarianism. The initial work on this subject after World War II was concerned with the potential fascist. At the time the data were collected the most extreme example of fascism in history had just been defeated in war. Interest was intense and it was the major concern of researchers to identify individuals who would readily accept fascism if it should become a strong or respectable social movement. In the opinion of many, no politico-social trend imposed a graver threat to traditional values and institutions than that of fascism, and knowledge of the personality forces that favor its acceptance would ultimately prove useful in combating it (Adorno, Frenke1-Brunswik, Levinson, and Sanford, 1950).

The authoritarian individual has been described by Masling (1954)

as one:

...who worries about egocentric and material things and thinks in terms of blame and appears to express aggression against the weak. Not only this, but authoritarians are conventional, submit uncritically in the face of authority, are anti-intraspective, superstitious, and stereotypic in their thinking, are preoccupied with the dominance-submission, strong-weak, leader-follower dimension, overemphasize the conventionalized attributes of the ego, have exaggerated assertions of strength and toughness, are cynical and destructive, tend to believe that wild and dangerous things go on in the world and have exaggerated concern with sexual 'goings on'. In addition, authoritarian men are overly masculine and women are overly feminine. ${ }^{1}$

- $\quad{ }^{J}$ Joseph M. Masling, "How Neurotic is the Authoritarian?" Journal of Abnormal and Social Psychology, 1954, 49(2), 316. 
Authoritarian individuals tend to be rigid and inflexible, intolerant to ambiguous situations, prejudiced, compulsive, punitive, aggressive to unconventional Individuals, and sometimes sadomasochistic.

As more data were collected, it was found that other dimensions, often associated with authoritarianism were personality variables in their own right and occurred apart from this single dimension. The analysis of tolerance-intolerance of ambiguity is an interesting personality variable of ten associated with authoritarianism yet it stands apart from it (Budnel, 1962; MacDonald, 1970).

\section{DEFINITION OF AMBIGUITY TOLERANCE}

In an effort to obtain an implicit definition of ambiguity, Norton (1975), consulted all of the articles dealing with ambiguity as referenced in the Psychological Abstracts from 1933 to 1970. After content analysis, efght categories emerged involving 125 uses of the term "ambiguous". Table I abstracts the categories and the percent of uses in each category (Norton, 1975).

An ambiguous situation may be defined as a situation which cannot be structured or categorized by the individual because of the lack of sufficient cues. Three types of ambiguous situations are suggested: a contradictory situation in which different elements or cues suggest differing conclusions, a completely new situation in which there are no familiar cues, and a complex situation in which there are a great number of cues to be taken into account (Budner, 1962).

Frenkel-Brunswik (1949) and Norton (1975) define intolerance of ambiguity as a tendency to perceive or interpret information that is vague, fragmented, incomplete, unstructured, uncertain, inconsistent, or contradictory as actual or potential sources of psychological threat. 
TABLE I

USES OF THE TERM AMBIGUOUS

\section{Category}

Percent of

Use

I. Multiple Meanings:

The stimulus was considered ambiguous by the researcher

$28 \%$

when it entailed at least two meanings, whether the person was aware or unaware of the multiple meanings, or clear or unclear about them.

II. Vagueness, Incompleteness, Fragmented:

If parts of the whole were missing, the stimulus was

designated as ambiguous. Examples include imcomplete line tracings or fragmented figures.

III. As a Probability:

A stimulus was treated as though it were ambiguous if it could $12 \%$ be analyzed as a function of a probability. Broen (1960), for instance operationalized ambiguity in terms of various combinations of interpretation response probabilities.

IV. Unstructured:

A stimulus which has no apparent organization or only partial $10 \%$ organization was considered ambiguous.

V. Lack of Information:

A situation in which there was no information or very little information was treated as an ambiguous situation.

VI. Uncertainty:

Ambiguous was equated to the state of mind it created-namely, uncertainty. In this sense, ambiguity was considered a consequent of a situation, event, interaction, etc.

VII. Inconsistencies, Contradictions, Contraries:

Any stimulus or stimulus set which entailed discrepant information was considered ambiguous. For example, if a set of Information suggested that something could be $X$ and not- $X$ at the same time, that set of information would be labeled ambiguous.

VIII. Unclear:

Sometimes ambiguous was used synonymously with the word unclear. $5 \%$ For example, McBride and Yoran (1967) defined something that is unambiguous as a dimension which may be summarized as the clarity of the statement. 
Ambigulty tolerance, on the other hand, is defined as the tendency to perceive ambiguous situations as challenging and desirable. Tolerant Individuals seek out and enfoy ambiguous situations and of ten excel in the performance of ambiguous tasks (MacDonald, 1970). However, Meek (1967) proposed that extreme tolerance of ambiguity could be manifested by Indifference, detachment, and lack of involvement. She states:

A person who is extremely tolerant of ambiguity may percelve ambiguous stimuli and become anxious but he deals with the aroused anxiety through various forms of withdrawal or denial. An individual extremely intolerant of ambiguity, on the other hand, reacts to the anxiety associated with ambiguity by attempting to do something actively about the ambiguity through such means as premature closure, extreme structuring, or through making definite commitments ... both of these forms of behavior can be maladaptive. 2

It is evident that the tolerance-intolerance continuum is not simply a case of separating the "good guys" from the "bad guys", but for the purpose of this paper and in accordance with the bulk of empirical evidence, ambiguity tolerance wi11 be considered a more adequate adjustment mechanism than ambiguity intolerance.

The problem of identifying tendencies to perceive ambiguous situations as potential sources of threat has been given some consideration by Budner (1962). He suggests that responses by an individual to stimuli takes place on at least two levels, the phenomenological and the operative. The phenomenological occurs in the world of Individual perceptions and feelings, while the operative remains in the world of natural and social objects. In one instance, the individual perceives, evaluates and feels

${ }^{2}$ Phyllis M. Meek, "Extreme Tolerance of Ambiguity: A Manifestation of Maladaptive Behavior," Diss. Abstracts, 1968, 29(3-B), 1162. 
(subjective), while in the other instance he behaves or acts in some manner w1th reference to the external environment (objective). Budner insists that by obtaining indicators of response on both levels, it is possible to achleve a more accurate estimate of an individual's tolerance-intolerance of ambiguity than can be derived from indicators limited to only one level of response.

Briefly, the range of possible reactions to threat may be classified rather crudely into submission anc denial. By submission it is meant that the ambiguous situation is recognizable as an ineluctable fact of existence which cannot be altered by the individual. By denial it is meant that the performance of some act by which the objective reality, even if only in the phenomenological world of the individual, is altered to suit the desires of the perceiver. Thus, it is plausible to infer that the Individual is in some way threatened if he exhibits one of the following types of response: phenomenological submission (anxiety and discomfort), operative denial (destructive or reconstructive behavior), and operative submission (avoldance behavior). If these behaviors are elicited by experiences and situations which are characterized by complexity, novelity, vagueness, inconsistance or insolubility, it would be plausible to assume that the individual is intolerant of ambiguity (Budner, 1962).

Traditionally, the concepts of rigidity and ambiguity intolerance have been confused -- often the terms are used interchangeably. However, Budner (1962) and MacDonald (1970) suggest that although the two concepts are related, they are theoretically and empirically separate. Ambiguity Intolerance suggests tendencies to relate to and interact in differing ways with certain classes of events or phenomena; rigidity, on the other 
hand, refers to a more generally pervasive singular response mode. A rigid Individual may be vlewed as one who perseverates in a spectfic response (in spite of contrary empirical evidence) whereas an intolerant person may be 11kely to replace one response with another. Example: An Intolerant person and a rigid person may both be anxious for closure in an amblguous situation and selze upon lmmediate answers or conclusions to the problematic situation. After accepting a selzed upon premature conciusion or answer, the rigid person will tenaciously hold to his opinion even in the face of contradictory evidence. The ambigulty intolerant person, on the other hand, will willingly exchange a premature conclusion for a more adequate one. As a result, an Individual may be intolerant of amblguity while remaining flexible although the two varfables are very often found together (Budner, 1962; MacDonald, 1970).

\section{PERSONALITY CORRELATES}

\section{Amblguity Tolerance}

Tolerance of ambigulty has been viewed historically as an adaptive cognitive control mechanism which possibly represents a capacity for dealing with open-ended or unstructured stimulus situations. It has been implied throughout the avallable literature that high tolerance of amblguity is in itself a valid index of underlying psychological health and adjustment (Foxman, 1976). Other adaptive personality trafts have been correlated with ambiguity tolerance also. These traits Include: tolerance for ethnic differences, tolerance for interpersonal conflict, disposition to Inhibit permature closure ("jumping to conclusions"), greater internal locus of evaluation, willingness to volunteer and experlence new and novel things, proficlency with ambiguous tasks, and a high 
but which turns out to be reality inadequate -- the environment simply is not organized around easily predictable determinates and an either/or approach.

Ambiguity intolerance has been correlated with many personality variables. However, not all personality variables correlated with ambiguity tolerance are always manifest with it. The reader should maintain high tolerance to this ambiguous personality variable to best understand its subtle constituents. Personality variables and behaviors often associated with ambiguity intolerance include: conventionality; need for structure; authoritarianism; ethnocentrism; dogmatism; rigidity; obsessional and perserverative tendencies; favorable attitudes toward censorship; asking for suggestions; belief in a divine power; prejudice; narrow-mindedness; manifest anxiety and guilt; low academic achievement; concreteness of thinking, constricted and inhibited; dislike of abstract art; premature need for closure, "jumping to conclusions"; and excessive avoidance of ambiguous situations (Budner, 1962; Chabassol, Thomas, 1975; Davids, 1955; Frenke1-Brunswik, 1949; MacDonald, 1970; Martin, 1954; Norton, 1975, 1976; O'Conner, 1952; Rehfisch, 1958; Rokeach, 1951; Troldah1, Powell, 1965). In addition, Budner (1962) found that medical students entering pediatrics or surgery were more intolerant of ambiguity than students entering psychiatry, suggesting that those who are intolerant of ambiguity tend to choose relatively structured professions. 
DEVELOPMENTAL HYPOTHESIS

The available literature is sparse with theoretical hypothesis for the origin of ambiguity intolerance-tolerance. The present author finds no theoretical explanation for the development of ambiguity tolerance and only one attempt by Frenkel-Brunswik (1949, 1950) to establish empirica1 evidence for the development of ambiguity intolerance.

Primary to Frenke1-Brunswik's concept of the development of ambiguity intolerance is the psychoanalytic concept of "ambivalence". In Freudian theory, ambivalence is defined as the coexistence, in the same individual, and of love and of hate-cathexis toward the same object. The existence of ambivalence and an Individual's ability to face his or her ambivalences toward others is considered a very important personality variable. Ability to recognize such coexistences is, in all probability, another personality variable apart from the concept of ambivalence. At one end of the continuum as defined by this ability, lies ambiguity intolerance - the tendency to resort to black or white solutions, to arrive at premature closure and to seek for unqualified and unambiguous acceptance or rejection of other people. Some individuals are more likely than others to see positive as we11 as negative features in their parents and can accept those feelings of love and hate with little display of anxiety or conflict. Others seem intent on dramatizing their image of their parents with the parent being viewed as altogether good or altogether bad.

In early childhood there are many rigid, external rules that a child must learn. Dichotomies customarily upheld in most homes include: dominance-submission, badness-goodness, cleanliness-dirtyness, and masculinity-femininity as well as a plethora of other less obvious 
dichotomies. The rigidity and extremity in which these dichotomies are viewed by the child seems contingent upon the extent to which the parent stresses these differences as well as the severity of discipline experlenced by the child for the nonadherence to his parents' view. Discipline experienced by children of intolerant parents typically is viewed as ego threatening, traumatic, overwhelming, and unintelligible as compared to more flexible homes where discipline is more intelligent and non-egodestructive. In homes with rigid orientation the discipline is more often based upon the expectation of a quick learning of external, rigid, superficial rules beyond the comprehension of the child. Family relationships tend to be based solely upon roles clearly defined in terms of dominance and submission (Levinson, 1949). It seems that the degree of toleranceintolerance depends upon the atmosphere of the home and expectations regarding the behavior of the child whether emphasis is placed upon quick action leading to tangible and concrete results with little understanding of finer discriminations or where progress toward higher developmental stages is encouraged especially with the development of insight. Reduction of fear and a tolerance toward weaknesses in the child would seem necessary to avoid rigidification of values. Other factors contributing to the "rigidification" of the personality would include extreme stress upon stereotyped behavior, an expectancy of self-negating submission, and an inducement to repress unacceptable tendencies.

Data from research by Frenkel-Brunswik (1949) suggests that parents of rigid, intolerant children tend to feel socially and economically marginal to the group from which they wish acceptance and the parents develop a desperate clinging to external and rigid rules. It seems likely that the less secure parents are in their feelings of belonging the more 
they will insist on maintenance of cultural norms both in themselves and In their children. This rigid adherence to norms provides the theoretical basis upon which the avoidance of ambiguity stands. In order to maintain complete adherence to norms and stereotyped patterns, certain aspects of experience must be avoided or suppressed from consciousness.

\section{MEASUREMENT OF AMBIGUITY TOLERANCE-INTOLERANCE}

There has been a variety of interest in the measurement of ambiguity tolerance-intolerance. The first attempt to measure tolerance of ambiguity was made by Frenkel-Brunswik (1949) in which a picture of a dog was shown and then followed by other pictures representing a gradual transformation of the dog into a cat. Individuals who maintained their original response despite contradictory empirical evidence were considered to be intolerant of ambiguity. However, as noted earlier by the present author, FrenkelBrunswik confounded the concept of ambiguity intolerance with rigidity, More recent attempts have been made to construct paper and pencil tests of ambiguity tolerance, but unfortunately the efforts have not met with a great deal of success. For example, Ehrlich (1965) substantially discredited Walk's A Scale when she reported it had no internal consistency. Likewise, ChIlds (1965) reforted an internal consistency $r$ of .16 (alpha coefficient) for his ambiguity tolerance scale.

In 1962 Budner developed a scale of ambiguity tolerance-intolerance that met with mild success. Soon after, Rydell and Rosen (1966) developed a scale which received revision by MacDonald (1970) and had a split-half reliability coefficient of .73 and a retest stability coefficient of .63 as well as showing evidence of construct validity. However, it was not 
unt1l Norton (1976) developed the Measure of Ambiguity Tolerance (MAT-50) that accurate measurement became a possibility (see Appendix A).

The MAT-50 was revised seven times, revising and combining some of the previous scales mentioned above. Internal reliability (KuderRichardson 20) for the final revision was an $r$ of .88 and a retest reliability (after three months) of .86. Norton (1975) hypothesized that if content validity was high on the MAT-50, high tolerant people should perceive themselves as such, and low tolerants, conversely. To test this hypothesis graduate students were asked to imagine, when completing the MAT-50, that they were very highly tolerant of ambiguity. Likewise the same number were asked to imagine that they were very Intolerant of ambiguity. The results revealed that those imagining they were extremely tolerant scored at the extreme end of the scale Indicative of tolerance of ambiguity. Imagined low tolerants likewise scored at the other extreme end of the scale. The results indicate that the MAT has high content validity.

Three different experiments provided substantial evidence for construct validity (Norton, 1975). The person who had high measured tolerance of ambiguity tended to volunteer for undefined experimenss more readily than intolerant individuals, likewise the person tended to use a different set of aesthetic judgments when viewing works of art. Tolerant Individuals preferred vague, abstract and impressionistic art over more defined and concrete art. Intolerant individuals tended to ask for suggestions in small group discussions more of ten than tolerant persons.

Obviously, these three experiments do not exhaust the research possibilities concerning the construct validity of the MAT-50. However, 
based upon the results of these studies, one should be able to be increasingly confident that the scale measures what it purports to measure (Norton, 1976).

EXPERIMENTAL METHOD AND TECHNIQUE

The present author proposed an experiment that would potentially lend construct validity to the MAT-50. The experiment consisted of determining tolerant and intolerant individuals as measured by the MAT-50, subjecting those individuals to an ambiguous situation and then measuring the degree of anxiety produced by the situation. Individuals who are Indicated as being intolerant of ambiguity by the MAT-50 should become more anxious than individuals whose MAT-50 scores indicate to be tolerant.

\section{Experimental Method}

Fifty individuals were administered the MAT-50, those individuals scoring one standard deviation above the mean were designated tolerant, while those scoring one standard deviation below the mean were designated intolerant. The State-Trait Anxiety Inventory was administered to the tolerant and intolerant individuals. Immediately following the administration of the State-Trait Anxiety Inventory the individuals were subjected to a group administration of the Rorschach. Traditional group Rorschach administration procedures were followed as outlined by Harrower and Steiner in Large Scale Rorschach Techniques (1973). Immediately following the administration of the group Rorschach, the State-Trait Anxiety Inventory was again administered. After scoring both administrations of the State-Trait Anxiety Inventory, statistical computations were performed consisting of an analysis of variance, two-factor mixed design, repeated measures on one factor. 


\section{Experimental Subjects}

Fifty student volunteers enrolled in introductory psychology courses were used as subjects in this experiment. Approximately 31 of the volunteers were female and approximately 19 were male. The age range was from $17-45$ years with a mean age of 25.6 years. There were 15 individuals in the intolerant group and 11 in the tolerant group.

\section{Experimental Rationale}

The group Rorschach has been chosen as an ambiguous situation due to its recognized ambiguity and its administrative facility as well as its measure of anxiety. However, the Rorschach does not distinguish between state and trait anxiety; therefore, its use as a measure of anxiety produced by intolerance of ambiguity is limited. Because of this limitation, the State-Trait Anxiety Inventory was administered giving measures of both long-term anxiety (trait) and transitory anxiety (state). The State-Trait Anxiety Inventory is known to be an effective measure of anxiety (Newmark, 1974). It was chosen for its ease of administration, rellability and validity. Spielberger (1970) adequately discusses the reliability and validity of the State-Trait Anxiety Inventory. Newmark, Hetzel and Frerking (1974) found that the mere process of taking the Rorschach produces an increase in the state anxiety that abates within twenty-four hours - trait anxiety remained unchanged after the administration of the Rorschach.

\section{Experimental Hypothesis}

The intolerant group will react to the ambiguous situation with greater state anxiety than the tolerant group. 


\section{Experimental Results}

The hypothesis was confirmed. Significantly more state anxiety was produced by the ambiguous situation in the intolerant group than the tolerant group at the .025 level of significance. Table II indicates the results of analysis of variance of state anxiety conditions. The intolerant group also showed more trait or long-term anxiety than the tolerant group (see Table III).

TABLE II

ANALYSIS OF VARIANCE - STATE ANXIETY

SOURCE

SS df

ms

F

$\mathbf{P}$

\begin{tabular}{|c|c|c|c|c|c|}
\hline TOTAL & 7,680 & 47 & - & 一 & 一 \\
\hline BETWEEN SUBJECTS & 4,772 & 23 & 一 & - & - \\
\hline Conditions & 402 & 1 & 402 & .133 & 0 \\
\hline Error $_{b}$ & 66,382 & 22 & 3,017 & - & - \\
\hline WITHIN SUBJECTS & 2,908 & 25 & - & - & 一 \\
\hline Trials & 221 & 1 & 221 & 2.483 & $<.20$ \\
\hline $\begin{array}{l}\text { Trials X } \\
\text { Conditons }\end{array}$ & 640 & 1 & 640 & 7.191 & $<.025$ \\
\hline Error $_{w}$ & 2,047 & 23 & 89 & - & - \\
\hline
\end{tabular}


TABLE III

ANALYSIS OF VARIANCE -- TRAIT ANXIETY

\begin{tabular}{|c|c|c|c|c|c|}
\hline SOURCE & ss & $\mathrm{d} \tilde{\mathbf{I}}$ & ms & $\mathbf{F}$ & $\mathbf{P}$ \\
\hline TOTAL & 7,264 & 47 & - & - & - \\
\hline BETWEEN SUBJECTS & 3,565 & 23 & 一 & 一 & - \\
\hline Conditions & 729 & 1 & 729 & .206 & 0 \\
\hline Error $_{b}$ & 77,743 & 22 & 3,534 & 一 & 一 \\
\hline WITHIN SUBJECTS & 3,699 & 25 & 一 & - & - \\
\hline Trials & 4 & 1 & 4 & .031 & 0 \\
\hline $\begin{array}{l}\text { Trials X } \\
\text { Conditions }\end{array}$ & 747 & 1 & 747 & 5.836 & $<.025$ \\
\hline Error & 2,948 & 23 & 128 & 一 & - \\
\hline
\end{tabular}

A slight trend is suggested indicating that some anxiety may have been produced by the ambiguous situation in tolerant individuals; however, this result only reaches the .20 level of significance - far below an acceptable criterion. Table 4 abstracts the results of testing with the MAT-50.

TABLE IV

ABSTRACT OF MAT-50 SCCRES

$N=50$

Age Range: $17-45 ;$ Mean Age $=25.6 ; 31$ Females; 19 Males

Mean Score $=3.53 \quad$ Variance $=.137$ Standard Deviation $\quad .370$

Standard Error of the Mean .054

Intolerants Scored $\leq 3.15 \quad$ Tolerants Scored $\geq 3.90$ 
The results of t-tests calculated on before and after anxiety scores indicate that no significant differences were apparent. However, a trend is suggested that state anxiety scores of the intolerant group were higher after the administration of the Rorschach than pre-Rorschach state anxiety scores $(t=2.13, d f=12, p<.10)$.

\section{CONCLUSIONS AND RECOMMENDATIONS}

The data of the present study corroborates the research by Norton (1975) Indicating that individuals intolerant of ambiguity react to ambiguous situations with anxiety. The present author has made a distinction between state and trait anxiety as measured by the State-Trait Anxiety Inventory (STAI). It appears that not only is short term anxiety produced when "intolerants" encounter ambiugity, as hypothesized, but the data also suggest that trait or long-term anxiety is more characteristic of "intolerants" than of "tolerants".

However, it is suggested that the Rorschach is not entirely responsible for elevated state anxiety scores in the intolerant group. Significance was only at the .10 level when pre- and post-Rorschach scores were compared, with post-Rorschach scores being higher. The opinion of the present author is that if the Rorschach were entirely responsible for the production of anxiety in the intolerant group, the level of significance would be much higher. The author postulates that intolerants found the entire testing situation anxiety producing, the Rorschach was only one ambiguous situation in several others. Other ambiguous situations In the testing environment could include the fact that subjects did not know what was to take place in the situation. The mere fact of not knowing what the individual volunteered for could produce anxiety. 
The State-Trait Anxiety Inventory contains potentially ego threatening statements of an individual's emotional state. The STAI could produce anxiety, especially if the individual did not know how the obtained information was to be used.

Further research is suggested using subjects from a population other than that of college students in introductory psychology classes. Subjects from populations delineated by occupation, age and religion may lend additional support to the present findings. Individuals attending institutions of higher education may provide a homogeneous sample lacking extreme tolerant or extreme intolerant individuals. For example, individuals making construction work their occupation as compared with those in the social sciences or individuals subscribing to narrow religious beliefs as compared with those with more flexible beliefs may provide a wider range of tolerance-intolerance than college students.

The results of the present study suggest that individuals who are intolerant of ambiguous situations find such situations anxiety producing. In addition, intolerant individuals may suffer more long-term or constant anxiety than intolerant individuals. The present study provides additional construct validation to the MAT-50. 


\section{BIBLIOGRAPHY}

Adorno, T.W.; Frenkel-Brunswlk, E.; Levinson, D.J.; Sanford, R.N. The Authoritarian Personality, New York: Harper, 1950.

Allport, Gordon; Ross, Michael. Personal religious orfentation and prejudice, Journal of Personality and Soclal Psychology, 1967, $5(4), 432-443$.

Baker, Therese L. The dimensions of nonauthorftarianism, Journal of Personality Assessment, 1976, 40(6), 626-634.

Batson, C. Daniel. Religion as prosocial: Agent or double agent? Journal for the Scientif1c Study of Religion, 1976, 151, 29-45.

Bishop, Marion R. Trusting behavior as related to rigidity and tolerance of ambiguity in the authoritarian, Dissertation Abstracts, 1967 , $28(5-B), 2153-2154$.

Bordin, Edward. Ambiguity as a therapeutic variable, Journal of Consulting and Clinical Psychology, 1955, 19(1), 9-15.

Brown, S. Soclal Psychology, New York: Free Press, 1965.

Budner, Stanley. Intolerance of ambigulty as a personality variable, Journal of Personality, 1962, 30(1), 20-50.

Chabassol, David. The measurement of some aspects of structure in adolescence, Journal of Educational Research, 1973, $66(6)$, 247-250.

Chabassol, David; Thomas, David. Needs for structure, tolerance of ambiguity and dogmatism in adolescents, Psychological Reports, $1975,37,507-510$.

Ch1ld, Irvin. Personality correlates of aesthetic judgment in college students, Journal of Persona11cy, 1965, 33, 476-511.

Crandall, James. Self-perception and interpersonal attraction as related to tolerance-intolerance of ambigutty, Journal of Personality, $1969,37,127-140$.

Crandall, James E. Effects of Intolerance of ambiguity upon interpersonal attraction, Psychological Reports, 1971, 28, 550 .

Davids, Anthony. Some personality and intellectual correlates of intolerance of ambigulty, Journal of Abnormal and Soctal Psychology, $1955,51,415-420$.

Digenan, Marillac; Murray, John B. Religious beliefs, religious comitment, and prejudice, Journal of Soclal Psychology, 1975, 97, 147-148. 
Ehrlich, Dantuta. "Intolerance of ambiguity", Walk's A Scale: Historical comment, Psychological Reports, 1965, 17, 591-594.

Foxman, Paul. Tolerance for ambiguity and self-actualization, Journal of Personality Assessment, 1976, 40(1), 67-72.

Frenkel-Brunswik, Else. Intolerance of ambiguity as an emotional and perceptual personality variable, Journal of Personality, 18, 1949, 108-143.

Harrower. M.R.; Steiner, M.E. Large Scale Rorschach Techniques; New York, C.C. Thomas, 1973.

Rlopfer, Bruno; Ainsworth, Mary; Klopfer, Walter; Holt, Robert. Deve1opments in the Rorschach Technique, New York: Harcourt, Brace and World, 1954 .

MacDonald, A.P. Revised scale for ambiguity tolerance: Reliability and validity, Psychological Reports, 1970, 26, 791-798.

Martin, Barclay. Intolerance of ambiguity in interpersonal and perceptual behavior, Journal of Personality, 1954, 22, 494-503.

Masling, Joseph M. How neurotic is the authoritarian? Journal of Abnormal and Social Psychology, 1954, 49(2), 316-318.

Meek, Phyllis M. Extreme tolerance of ambiguity: A manifestation of maladaptive behavior, Dissertation Abstracts, 1968, 29(3-B), 1162-1163.

Morrow, William. Rigidity of attitudes regarding personal habits and its 1deological correlates, Journal of Abnormal and Social Psychology, 1954, 49; 89-93.

Newmark, Charles; Hetzel, W.; Frerking, R. The effects of personality tests on state and trait anxiety, Journal of Personality Assessment, $1974,38(1), 17-20$.

Norton, Robert. Manifestations of ambigulty tolerance through verbal behavior in small groups, Communication Monographs, 1976, 43, 35-43.

Norton, Robert. Measure of Ambiguity Tolerance, Journal of Personality Assessment, 1975, 39(6), 607-619.

0'Connor, Patricia. Ethnocentrism, "intolerance of ambiguity" and abstract reasoning ability, Journal of Abnormal and Social Psychology, 1952, 47, 526-530.

Rehfisch, John M. A scale for personality rigidity, Journal of Consulting Psychology, 22(1), 1958, 11-15. 
Rokeach, M. Generalized mental rigidity as a factor in ethnocentrism, Journal of Abnormal and Social Psychology, 1943, 48, 259-278.

Rokeach, Milton. Prejudice, concreteness of thinking, and reification of thinking, Journal of Abnormal and Socla1 Psychology, 1951, $46,83-91$.

Rotter, J. Generalized expectancies of internal versus external control of reinforcement, Psychological Monographs: General and Applied, $1966,80(1)$.

Ryde11, Susan. Tolerance of ambiguity and semantic differential ratings, Psychological Reports, 1966, 19, 1303-1312.

Shavit, Hana. Personality adjustment as a function of interaction between locus of evaluation and tolerance of ambiguity, Psychological Reports, $1975,37,1204-1206$.

Spielberger, C.D.; Gorsch, R.L.; and Luchene, R. Manual for the StateTrait Arixiety Inventory, Palo Alto, California: Consulting Psychologists Press, 1970.

Troldahl, Verling C.; Powe11, Fredric A. A short form dogmatism scale for use in field studies, Social Forces, 1965, 44(2), 211-214. 
APPEND IX

$$
\text { MAT - } 50
$$

\section{DIRECTIONS:}

Block out the box on the answer sheet that best answers the following questions. Use the following rating scale:

(1) always true, (2) mostly true, (3) more true than false, (4) equally true and false, (5) more false than true, (6) mostly false, (7) always false.

1. Almost every problem has a solution.

2. I like to fool around with new Ideas, even if they are a total waste of time.

3. Nothing gets accomplished in the world unless you stick to some basic rules.

4. I do not belleve that in the final analysis there is a difference between right and wrong.

5. Usually, the more clearly defined rules a soclety has, the better off it is.

6. Personally, I tend to think that there is a right way and a wrong way to do almost everything.

7. I prefer the certainty of always being in control of myself.

8. I tend to be very frank with people.

9. It Irks me to have people avold the answer to my question by asking another question.

10. I really dislike it when a person does not give straight answers about himself.

11. It really disturbs me when I am unable to follow another person's train of thought.

12. I prefer telling people what I think of them even if it hurts them; rather than keeping it to myself.

13. It would bother me if different close friends of mine had conflicting opinions of me.

14. I always want to know what people are laughing at. 
15. It Intensely disturbs me when I am uncertain of how my actions affect others.

16. It bothers me when I don't know how strangers react to me.

17. I function very poorly whenever there is a serious lack of communIcation in a job situation.

18. In a situation in which other people evaluate me, I feel a great need for clear and explicit evaluations.

19. If I am uncertain about the responsibilities of a job, I get very anxtous.

20. If I were a scientist, I migk:t become frustrated because my work would never be completed (sclence will always make new discoveries).

21. If I were a doctor, I would prefer the uncertainties of a psychiatrist to the clear and definite work of someone like a surgeon or X-ray specialist.

22. Once I start a task, I don't like to start another task until I finish the first one.

23. Before any important job, I must know how long it will take.

24. In a problem-solving group, it is always best to systematically attack the problem.

25. A problem has little attraction for me if I don't think it has a solution.

26. I do not 1ike to get started in group projects unless I feel assured that the profect will be successful.

27. In a decision-making situation in which there is not enough information to process the problem, I feel very uncomfortable.

28. I don't like to work on a problem unless there is a possibility of coming out with a clear-cut and unambiguous answer.

29. Complex problems appeal to me only if I have a clear Idea of the total scope of the problem.

30. A group meeting functions best with a definite agenda.

31. I seem to enjoy parties the most when I know most of the people there.

32. Before going to a party, I always want to know what kind of a party It Is.

33. I get pretty anxious when I'm in a social situation involving me which I have little control of. 
34. Whenever I am in a new group, I usually take the initiative in introducing myself.

35. First impressions tend to be very Important to me.

36. Whenever I go out to have fun, I like to have at least a vague purpose in mind.

37. I am fust a little uncomfortable with people unless I feel that I can understand their behavior.

38. I don't feel comfortable with people until I can find out something about them.

39. I have a good Idea of exactly how many friends I could really count on.

40. I like to know ahead of time what will be for dinner.

41. Whenever I go on a long trip, I like to keep track of the miles to go.

42. I will not consider buying an item unless the price is clearly marked on $1 t$.

43. It matters to me to know what day it is.

44. I get very anxious wafting to hear the electlons results.

45. I usually like to know what time it is.

46. I want to know what a salesman is selling before I'11 listen to him.

47. It really bothers me when a person shows up late for an appointment without an explanation.

48. If I don't get the punch line of a joke, I don't feel right until I understand it.

49. I enfoy carefully rehashing my conversations in my mind afterwards.

50. Before going out, I always check my appearance to make sure I look right.

51. I am tolerant of ambiguous situations.

52. The best part of working a figsaw puzzle is putting in that last piece.

53. I tend to like obscure or hidden symbolism.

54. Mysticism is too abstract and undefined for me to take seriously.

55. If I miss the beginning of a good movie, I like to stay to see the start of it. 
56. Vague and impressionistic pictures appeal to me more than realistic pictures.

57. I tend to prefex plctures with perfect balance in the composition.

58. I like movles or storles with definite endings.

59. Generally, the more meanings a poem has, the better I 1ike it.

60. A poem should never contain contradictions.

61. In the final analysis, the correct interpretation of a poem or story is the author's interpretation. 